Provided for non-commercial research and education use. Not for reproduction, distribution or commercial use.

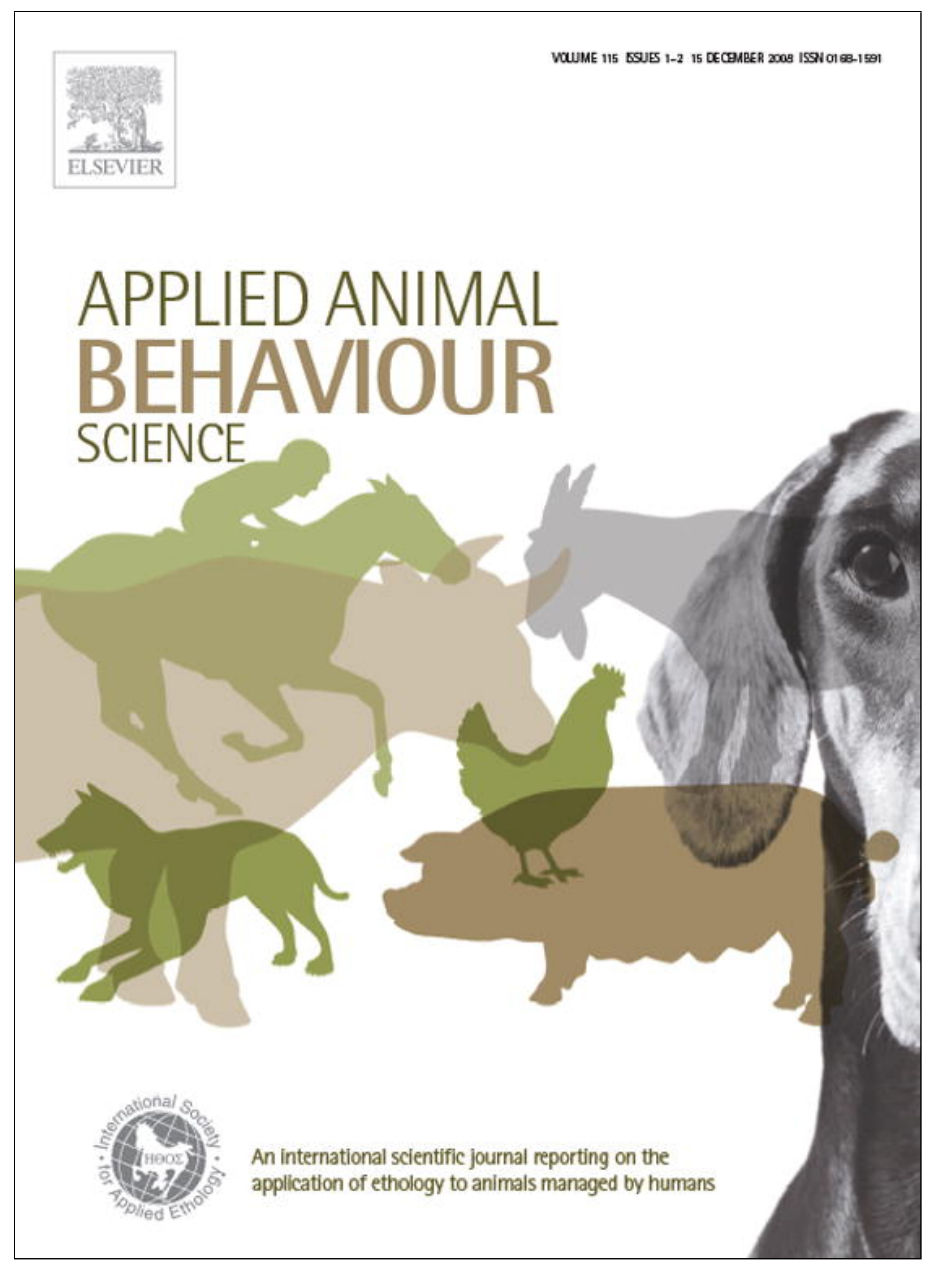

This article appeared in a journal published by Elsevier. The attached copy is furnished to the author for internal non-commercial research and education use, including for instruction at the authors institution and sharing with colleagues.

Other uses, including reproduction and distribution, or selling or licensing copies, or posting to personal, institutional or third party websites are prohibited.

In most cases authors are permitted to post their version of the article (e.g. in Word or Tex form) to their personal website or institutional repository. Authors requiring further information regarding Elsevier's archiving and manuscript policies are encouraged to visit:

http://www.elsevier.com/copyright 


\title{
The effects of surgical and chemical castration on intermale aggression, sexual behaviour and play behaviour in the male ferret (Mustela putorius furo)
}

\author{
Claudia M. Vinke ${ }^{\mathrm{a}, *}$, Remko van Deijk ${ }^{\mathrm{b}}$, \\ Bart B. Houx ${ }^{\text {a }}$, Nico J. Schoemaker ${ }^{b}$ \\ ${ }^{a}$ Department of Animals, Science \& Society, Division of Ethology \& Welfare, \\ Faculty of Veterinary Medicine, University of Utrecht, The Netherlands \\ ${ }^{\mathrm{b}}$ Department of Clinical Sciences of Companion Animals, Division of Avian and Exotic Animal Medicine, \\ Faculty of Veterinary Medicine, University of Utrecht, The Netherlands
}

Accepted 6 May 2008

Available online 16 June 2008

\begin{abstract}
The ferret (Mustela putorius furo) has become an increasingly popular pet animal, yet little is known about their behaviour and welfare. Inter- and intra-specific aggression and the intense musky scent are the two main reasons why male ferrets are normally surgically castrated. However, it is this neutering that is thought to play an important role in the development of hyperadrenocorticism, a hyperfunctioning of the adrenal cortex due to neoplastic changes, a common disease in domestic ferrets. An alternative to surgical castration might be the slow releasing GnRH agonist deslorelin implant (chemical castration).

The present study aimed to examine the effects of the deslorelin implant and surgical castration on the occurrence of intermale aggression, sexual behaviour and play behaviour in male ferrets. Therefore, 21 male domestic ferrets received either an implant containing deslorelin $(n=7)$, a placebo implant $(n=7)$, or were surgically castrated $(n=7)$.

Our data showed that: (1) chemical castration with the GnRH agonist deslorelin results in a decrease in the occurrence of aggressive behaviour between male ferrets both in the presence and absence of a receptive female. In addition, our data showed that a deslorelin castration had more effect on the reduction of aggression than surgical castration; (2) sexually motivated behavioural patterns were reduced in the deslorelin and surgical castrated group in the male-female confrontation; (3) the deslorelin group, and to a lesser extent the surgically castrated group, had a higher incidence of play behaviour in comparison to intact males in the intermale confrontation tests. Therefore, deslorelin chemical castration is a suitable alternative
\end{abstract}

\footnotetext{
* Corresponding author at: Department of Animals, Science \& Society, Faculty of Veterinary Medicine, University of Utrecht, P.O. Box 80166, 3508 TD Utrecht, The Netherlands. Tel.: +31 30 2534373; fax: +31 302539227.

E-mail address: c.m.vinke@uu.nl (C.M. Vinke).
} 
for surgical castration, and may even be preferred due to the serious medical problems associated with surgical castration in ferrets. Especially the increase of play behaviour might be indicative for an improved welfare of the ferrets.

(C) 2008 Elsevier B.V. All rights reserved.

Keywords: Ferret; Castration; Intermale aggression; Play behaviour; Welfare

\section{Introduction}

The ferret (Mustela putorius furo) has become an increasingly popular pet animal, yet little is known about their behaviour and welfare. In veterinary practice, two topics are reported regularly: (1) inter- and intra-specific aggression (e.g. Applegate and Walhout, 1998; Staton and Crowell-Davis, 2003; Quesenberry and Carpenter, 2004, p. 83) and (2) the intense musky scent of the males (Quesenberry and Carpenter, 2004, p. 83). In pet industry, these two mentioned characteristics of ferrets often result into repetitive rehousing, sheltering, or even euthanasia. Additionally, aggressive interactions in mustelids can be violent with a high risk of injuries (Poole, 1966, 1973, 1974; Dunstone, 1993). Thus, frequent aggressive interactions between socially housed pet ferrets may seriously decrease their welfare.

In the Netherlands, male ferrets are normally surgically castrated before the age of 1 year (see Schoemaker et al., 2000) to reduce interspecific and intraspecific aggression and to reduce the musky scent they spread. However, it is this castrating that is thought to play an important role in the development of hyperadrenocorticism, a common disease in the domestic ferret. There are several reasons to assume that continuously high concentrations of especially luteinising hormone $(\mathrm{LH})$ can result in adrenocortical hyperplasia, proliferation of cells in the adrenal cortex, or tumorigenesis, formation of tumors, associated with hyperadrenocorticism (see Schoemaker et al., 2000, 2002; Wagner et al., 2001).

Little is reported on the effects of castration on aggressive behaviour in ferret so far. The only available study is of Staton and Crowell-Davis (2003) who reported no difference in aggressive behaviour between surgically castrated and intact male pairs. However, they mentioned their small numbers of pairings as a possible explanation for this lack of significance. Though some analogical studies on dogs found that surgical castration decreases aggression (e.g. Beaver, 1983; Wright and Nesselrote, 1987) the evidence on the effectiveness of castration on the aggression of male ferrets seems scarce, if not unavailable. In general, decreased levels of plasma LH and testosterone concentration are presumed to result in a decrease of intermale aggression and of sexual behaviour (Baum, 1976; Baum et al., 1983; Carroll et al., 1988; Lambert and Baum, 1991; Giammanco et al., 2005).

A potential alternative for surgical castration in the male ferret may be an implant containing the long acting and slow releasing GnRH (gonadotrope releasing hormone) agonist deslorelin (Suprelorin ${ }^{\mathbb{R}}$, Peptech Animal Health, Sydney, Australia) (chemical castration). The effect of a GnRH agonist implant consists of two phases. During the initial (acute) phase, LH plasma concentrations increase, simultaneously resulting in an initial rise of the plasma testosterone concentration (D'Occhio et al., 2000). Depending on the species and the administered dose of GnRH agonist, the course of the second, chronic phase can be different. In the stallion implantation of deslorelin leads, after the initial elevation of LH and testosterone, to a decrease of LH and testosterone below the levels of the control animals around day 13 after implantation 
(Johnson et al., 2003). After implantation of dogs with deslorelin, plasma testosterone concentrations decreased within 6-25 days below $1 \mathrm{ng} / \mathrm{ml}$. This concentration was maintained for 3 months to 2.7 years (Trigg et al., 2001). In the bull, GnRH agonist deslorelin treatment leads to a down regulation of the pituitary function, indicated by the decrease of pulsatile release of LH. Plasma testosterone concentration, in contrast, is elevated (Ronayne et al., 1993; D'Occhio and Aspden, 1996; D'Occhio et al., 2000).

Thus, although not fully conclusive, deslorelin implants may decrease levels of LH in the male ferret, which can result in a decreased risk of adrenocortical hyperplasia or tumorigenesis, and a decrease of intermale aggression and sexual behaviour.

Although the GnRH agonist deslorelin might be an alternative for surgical castration, there are no reports on the effect of deslorelin on behaviour in ferrets. Therefore, our first aim was to examine the effects of the deslorelin implant on the occurrence of intermale aggression, sexual behaviour and play behaviour in male ferrets. A second aim was to assess the effect of surgical castration on aggression in male ferrets in general, as in the literature little is reported on such effects. Therefore, the behaviour of the males from one group of ferrets with a deslorelin implant (chemically castrated) was compared to one group of surgically castrated ferrets and to one group of intact (placebo implanted) ferrets. The ferrets were observed in three experiments of pair-wise confrontations ("confrontation tests").

It was hypothesized that plasma concentrations of both LH and testosterone will decrease after placement of the deslorelin implant in ferrets, resulting in a decrease of intermale aggression and sexual behaviour (Baum, 1976; Baum et al., 1983; Carroll et al., 1988; Lambert and Baum, 1991; Giammanco et al., 2005). Additionally, it was hypothesized that the reduced aggression would result in a less stressful environment and hence, in an increase of play behaviour. Increased incidences of play might indicate on increased welfare (see e.g. Hinton and Dunn, 1967; Fagen, 1981; McCune, 1992; Grier and Burk, 1992; Broom and Johnson, 1993; see for opioid release during play: Vanderschuren et al., 1995a,b; see for a discussion on play behaviour and welfare in farmed mink: Vinke, 2004; Vinke et al., 2005). Additional effects of the treatments on hormone levels (plasma testosterone and FSH), testis volumes, histological examination of the testes and a control for differences in musky scents are presented elsewhere (Schoemaker et al., 2008).

\section{Materials and methods}

All experiments were performed in adherence to the legal requirements of the Netherlands (Animal Experimentation Act, 1977) and have been approved by Ethics Committee of the Faculty of Veterinary Medicine, Utrecht University, The Netherlands.

\subsection{Animals, housing and experimental groups}

Twenty-one commercially bred male ferrets between the age of 1 and 2 years were individually housed in outdoor suspended wire meshed home cages (dimensions: $88 \mathrm{~cm}(L) \times 30 \mathrm{~cm}(W) \times 46 \mathrm{~cm}(H)$ ) with a nest box (dimensions: $29 \mathrm{~cm}(L) \times 34 \mathrm{~cm}(W) \times 23 \mathrm{~cm}(H))$ filled with pea straw. Pellets $\left(\right.$ FerRet $^{\mathrm{R}}{ }^{\mathrm{B}}$, Hope Farm, Woerden, The Netherlands) and water were available ad libitum.

For the experiment, the 21 ferrets were randomly assigned to three groups $(N=7$ per experimental group):

- Placebo group. Group of males with a placebo implant (placebo control group; mean [ \pm S.D.] body weight: $1.5 \pm 0.1 \mathrm{~kg}$; range: $1.3-1.7 \mathrm{~kg}$ ). 
- Deslorelin-implant group. Group of males with a deslorelin implant containing $9.4 \mathrm{mg}$ deslorelin (chemically castrated experimental group; mean [ \pm S.D.] body weight: $1.5 \pm 0.1 \mathrm{~kg}$; range: $1.3-1.7 \mathrm{~kg}$ ).

- Castrate group. Group of males that were surgically castrated (surgically castrated control group; mean [ \pm S.D.] body weight: $1.4 \pm 0.2 \mathrm{~kg}$; range: $1.0-1.6 \mathrm{~kg}$ ).

The female ferrets that were used as test stimuli in the confrontations tests 2 and 3 (see Section 2.3) were housed in exactly the same way as the male ferrets mentioned above. In their standard housing conditions males and females were visually and physically separated by three empty cages between the groups.

\subsection{Start procedures}

\subsubsection{Vaccination and physical control}

All ferrets underwent a weekly procedure of blood sampling and testis measurements (see for detailed information: Schoemaker et al., 2008). During one of these standard checks they were vaccinated against Canine Distemper Virus with Nobivac Puppy DP (Intervet Nederland B.V. Boxmeer, The Netherlands).

\subsubsection{Castration}

The ferrets of the 'castrate group' were surgically castrated 7 weeks before the behavioural observations started. Anaesthesia was induced in all ferrets by a mask with $4 \%$ isoflurane $\left(\mathrm{IsoFlo}^{\mathrm{TM}}\right.$, Abbott Animal Health, Hoofddorp, The Netherlands) in 100\% oxygen and maintained at $2 \%$ isoflurane during the procedure. Analgesia was provided with carprofen $4 \mathrm{mg} / \mathrm{kg}$ (Rimadyl ${ }^{\mathbb{R}}$, Pfizer, Capelle a/d IJssel, The Netherlands) and buprenorphine $0.01 \mathrm{mg} / \mathrm{kg}$ (Temgesic ${ }^{\mathbb{R}}$, Schering-Plough, Utrecht, The Netherlands).

The total testis volume of one ferret in the placebo implant group did not increase and was comparable with that of ferrets in the deslorelin-implant group. Based on histological evaluation of the left testis (an arrest of spermatogenesis at the level of meiosis), this ferret was diagnosed with hypogonadism, i.e. a condition in which insufficient testosterone is produced, unrelated to this study. This ferret was therefore removed from the dataset and was not used for further statistical analyses.

\subsubsection{Implants}

The animals of the 'deslorelin-implant group' and 'placebo group' received the implants on the same day that the surgical castrations were performed in the 'castrate group'. The deslorelin implants were manufactured by Peptech Animal Health, Sydney, Australia and contained $9.4 \mathrm{mg}$ deslorelin (Suprelorin ${ }^{\circledR}$ ). The implants, either deslorelin or placebo, were administered subcutaneously in the interscapular space using an implanting device provided with the implants. The skin at the injection site was then sealed with tissue glue (Vet-Seal ${ }^{\mathbb{R}}$, B. Braun Medical, Emmenbrücke, Switzerland). The implants were placed at the same time as the blood collection.

\subsection{Experimental methods and treatments}

Subsequently, three "confrontation tests" were carried out to evaluate aggressive behaviour, play behaviour and male sexual behaviour. All males from each experimental group were confronted with a male of the same experimental group in an experimental test area both in the absence (confrontation test 1 ) and in the presence of a receptive female (confrontation test 2). The subjects were, if necessary, marked with CTC (chlorotetracycline) fluorescent spray to facilitate individual recognition. In confrontation test 3 , the sexual motivation of the males was tested in a male-female confrontation.

\subsubsection{Test area}

The test area for the confrontation tests was a roofed outdoor dog kennel (dimensions: $150 \mathrm{~cm}$ $(L) \times 115 \mathrm{~cm}(W) \times 200 \mathrm{~cm}(H))$. This test area was separated from the standard housing conditions of the ferrets by a wooden door. The area was divided into two compartments by a transparent plastic plate with 
Table 1a

Ethogram used in experiments 1 and 2 to score the male ferret behaviour (adapted from Poole, 1974, 1978)

\begin{tabular}{|c|c|c|}
\hline Main pattern & Contains & Description \\
\hline \multirow[t]{9}{*}{ Offensive behaviour } & Positions for attack & $\begin{array}{l}\text { Orientation to reach a position from which } \\
\text { an attack may be launched }\end{array}$ \\
\hline & Attack & $\begin{array}{l}\text { Movement into a position from which } \\
\text { the neck or ear regions of the opponent may } \\
\text { be bitten. Attacker crosses over its opponent's } \\
\text { back to reach the far side of the neck so that } \\
\text { the attack is generally from above }\end{array}$ \\
\hline & Neck bite & Bites opponent in the neck and holds \\
\hline & Bite other & $\begin{array}{l}\text { Bites to other places (for example: flank, } \\
\text { belly, anal) }\end{array}$ \\
\hline & Drag & $\begin{array}{l}\text { Grips opponent by the neck with teeth and } \\
\text { pulls it around (neck bite is implied) }\end{array}$ \\
\hline & Shake & $\begin{array}{l}\text { Animal bites in a body part of another animal } \\
\text { and shakes violently with the head up and } \\
\text { down and from right to left (neck bite is implied) }\end{array}$ \\
\hline & Oblique attack with physical contact & $\begin{array}{l}\text { Approach to the opponent from the side } \\
\text { or behind. The attacker's head is turned } \\
\text { away from its adversary and its back } \\
\text { arched attacker pushes its flank against } \\
\text { its adversary and may roll on to it }\end{array}$ \\
\hline & Position for lunge attack & $\begin{array}{l}\text { Orientation to a position from which } \\
\text { a lunge attack van be launched }\end{array}$ \\
\hline & Lunge attack with contact & $\begin{array}{l}\text { Lunges towards the opponent directing the } \\
\text { open mouth towards the near side of the } \\
\text { opponent's neck and touches opponent's } \\
\text { fur, sometimes results in a bite }\end{array}$ \\
\hline \multirow[t]{8}{*}{ Defensive behaviour } & Ward off & $\begin{array}{l}\text { Flank is directed towards an adversary, the } \\
\text { head turned away so that the convex side } \\
\text { of the neck is presented to the opponent. } \\
\text { Generally in response to an attack }\end{array}$ \\
\hline & Extricate & $\begin{array}{l}\text { Any movements made by an animal to } \\
\text { free itself from its opponent's bite. } \\
\text { May include rolling, kicking, scratching } \\
\text { with forepaws, brief attacks }\end{array}$ \\
\hline & Extricate with vocalization & $\begin{array}{l}\text { As for extricate but the animal makes } \\
\text { high pitch vocalization that sound } \\
\text { like screaming }\end{array}$ \\
\hline & Defensive & Faces the opponent with back arched \\
\hline & Defensive threat & $\begin{array}{l}\text { As for defensive but accompanied with } \\
\text { vocalizations (vocalizations accompanying } \\
\text { different levels of intensity are hiss, scream) }\end{array}$ \\
\hline & Snap & $\begin{array}{l}\text { Biting movements made without any attempt } \\
\text { actually to bite the opponent }\end{array}$ \\
\hline & Passive & $\begin{array}{l}\text { The animal that is being bitten makes } \\
\text { no attempts to free itself from the opponents grip }\end{array}$ \\
\hline & Scream & Animal vocalizes with high pith tones \\
\hline Social behaviour (other) & $\begin{array}{l}\text { Investigate ano-genital } \\
\text { Investigate neck-nose } \\
\text { Investigate nose-nose } \\
\text { Nose push }\end{array}$ & $\begin{array}{l}\text { Sniffing another animal on ano-genital region } \\
\text { Sniffing another animal in the neck/ear region } \\
\text { Sniffing another animal on the nose } \\
\text { Animal pushes with nose into the flank of } \\
\text { the opponent }\end{array}$ \\
\hline
\end{tabular}


Table 1a (Continued)

\begin{tabular}{|c|c|c|}
\hline Main pattern & Contains & Description \\
\hline \multirow[t]{2}{*}{ Play behaviour } & Locomotory play & $\begin{array}{l}\text { Play behaviour consisting out of gallop forward } \\
\text { (bouncing jerky gait), gallop away, leap over the } \\
\text { opponent, jump on the opponent }\end{array}$ \\
\hline & Rough and tumble play & $\begin{array}{l}\text { Play behaviour by which the animal may } \\
\text { roll over, pushes with paws, ward of with } \\
\text { paw, inhibited chin biting }\end{array}$ \\
\hline \multirow[t]{16}{*}{ Other behaviour } & Back away & $\begin{array}{l}\text { Movement away from the opponent whilst } \\
\text { remaining facing it }\end{array}$ \\
\hline & Face & Facing the opponent \\
\hline & Evade & $\begin{array}{l}\text { Movements away from the opponent (in step), } \\
\text { while not facing opponent }\end{array}$ \\
\hline & Flee & $\begin{array}{l}\text { Movement away from the opponent (in gallop) } \\
\text { while not facing opponent }\end{array}$ \\
\hline & Follow & $\begin{array}{l}\text { Follows opponent while he backs } \\
\text { away/evades (walking) }\end{array}$ \\
\hline & Chase & $\begin{array}{l}\text { Animal follows opponent while he backs } \\
\text { away/evades (galloping) }\end{array}$ \\
\hline & Approach & Animal increase proximity to opponent \\
\hline & Explore & $\begin{array}{l}\text { Walking around, sniffing and scratching at } \\
\text { the walls or floor }\end{array}$ \\
\hline & $\begin{array}{l}\text { Explore box } \\
\text { (only in experiment } 2 \text { ) }\end{array}$ & $\begin{array}{l}\text { Sniffing, scratching, climbing on the box } \\
\text { with the female }\end{array}$ \\
\hline & Prostration & $\begin{array}{l}\text { Flattens itself on the ground with head down, } \\
\text { front paws pointing forward and hind } \\
\text { legs splayed out on the ground }\end{array}$ \\
\hline & Defecating & Animal defecates or urinates \\
\hline & Rubbing & $\begin{array}{l}\text { Animal rubs the ground or wall with face or } \\
\text { neck and may roll over }\end{array}$ \\
\hline & Fur shake & Animals shakes off water of fur \\
\hline & Grooming & $\begin{array}{l}\text { Animal licks or rubs its pelt with forepaws } \\
\text { and tongue }\end{array}$ \\
\hline & Coughing & Animal coughs/sneezes \\
\hline & Alert & Animal actively observes surrounding \\
\hline
\end{tabular}

The behavioural pattern 'explore box' was only used in experiment 2 .

small holes in it (diameter of each hole: $1 \mathrm{~cm}$; placed in three rows: one $5 \mathrm{~cm}$ from the ground, one $40 \mathrm{~cm}$ from the ground and one in between; the holes were $8 \mathrm{~cm}$ apart). The holes made it possible for the ferrets to smell each other before the actual confrontation. After every confrontation test, the area was cleaned intensively with water to get rid of the urine and faeces of the previous pair of ferrets.

\subsubsection{Confrontation tests}

The confrontation tests, which lasted 10 min each, were carried out between 8:30 and 16:00 h during May. In experiments 1 and 2, each subject was tested in pairs with all males from the same group except its direct neighbours, which resulted in three tests per male (one animal of each group was tested four times because of the number of ferrets used). Neighbours were never paired with each other, to rule out possible influences of familiarity (see Poole, 1973). Pairs of every group were tested at random times throughout 8 consecutive days (except for the weekend) to rule out circadian changes in behaviour, or influences related to the standard management procedures. The total number of tests was 87 (8-9 tests per day): 33 in confrontation test 1, 33 in confrontation test 2 and 21 in confrontation test 3 . All tests 
Table $1 \mathrm{~b}$

Additional behavioural patterns for the ferret ethogram used for the observation of the male's sexual motivated behaviour in experiment 3

\begin{tabular}{lll}
\hline Main pattern & Contains & Description \\
\hline Male sexual behaviour & Neck grip & Male bites the female in the neck and \\
& Mounting & $\begin{array}{l}\text { holds (NB: see comment in Section 2.4.1) } \\
\text { Male holds female with a neck grip and } \\
\text { tries to mount her }\end{array}$ \\
Other behaviour & Intervention & $\begin{array}{l}\text { Observers intervenes on the moment the male } \\
\text { has mounted or is trying to mount the female }\end{array}$ \\
\hline
\end{tabular}

were recorded on video by a digital camera (Panasonic NV-GS15EG) that was mounted above the test area.

2.3.2.1. Procedures of experiment 1: confrontation test male-male without receptive female. To evaluate the spontaneous aggressive behaviour and play behaviour between male ferrets, a first confrontation test was carried out in the absence of receptive female ferret. Each 10 min confrontation test started as soon as two interaction partners were placed in the testing area, separated by the transparent plastic plate. After 2 min the plate was removed and full physical contact was possible during $8 \mathrm{~min}$, after which the experiment was ended and the ferrets were returned to their cages (an unpublished pilot experiment showed that at least $5 \mathrm{~min}$ are necessary to observe interactions between the ferret males, therefore, we decide for a full contact period of $8 \mathrm{~min}$ ). Three females were used as test stimuli in the confrontation tests 2 and 3 . The receptiveness of each female was assessed each day by controlling the swelling of the vulva. These females were randomly used during the confrontation tests.

2.3.2.2. Procedures of experiment 2: confrontation test male-male in the presence of receptive female. To enhance the potential aggressive motivation of the male ferrets, a second confrontation test was carried out in the presence of a receptive female ferret. The female in oestrus was placed in a transport box (plastic box of $40 \mathrm{~cm}(L) \times 30 \mathrm{~cm}(W) \times 30 \mathrm{~cm}(H)$ with several open spaces through which olfactory stimuli and some visual stimuli could be exchanged) in the middle of the testing area in order to elicit more competition between the males.

The test started as soon as one male-male pair was placed in the testing area with the transparent plastic plate to separate them. After 2 min the plate was lifted and a receptive female ferret in a transporting box was placed in the middle of the testing area. The experiment was ended after $8 \mathrm{~min}$ and the subjects were returned to their cages.

2.3.2.3. Procedures of experiment 3: male sexual behaviour in a male-female confrontation. In this third experiment the male sexual behaviour was evaluated. Each of the male ferrets $(N=21)$ was confronted with a female ferret in oestrus. The test started as soon as the subjects were put in the testing area separated by the plastic transparent plate for $2 \mathrm{~min}$, after which the plate was removed and 8 min full physical contact was possible. To avoid the risk of ovulation induction in the females, intervention took place if a male mounted the female for pelvic thrusting.

\subsubsection{Behavioural observations}

Table 1a shows the ethogram used to score the behaviour in the male-male interactions in experiments 1 and 2 . Table $1 \mathrm{~b}$ shows the additional ethogram used to score the sexual behavioural patterns in the malefemale interactions in experiment 3 . The observed behavioural patterns were mutually exclusive. 


\subsection{Data analysis and statistics}

\subsubsection{Data analysis}

The videos were analysed afterwards by one observer. The observer was "blind" with regard to the experimental condition, but cues in the recordings often allowed an educated guess. The behavioural patterns were scored with the use of a focal animal sampling method with The Observer 5.0 software (Noldus Information Technology, Wageningen, The Netherlands). The tape was played at normal speed.

Only the behaviour in the $8 \mathrm{~min}$ of true interaction was scored (i.e. after the plastic transparent plate was removed). For a more accurate statistical analysis, the data of some separate behavioural patterns were lumped together into a behavioural class. The behavioural classes were defined as follows:

(1) 'Total offensive and defensive' consists the mean duration of the sum of all offensive and defensive behaviour patterns, that is: passive, defensive, defensive threat, extricate, extricate with scream, position for lunge attack, lunge attack, oblique attack, shake, drag, neck bite, attack, position for attack and scream. Defensive behaviour is often evoked by aggressive behaviour of the opponent, so combining these two behavioural classes leads to an overall insight in agonistic behaviour. Two behavioural subclusters which prominently present aggression are elucidated in more detail:

(a) 'Total offensive' is the combined behavioural sub-class of the total durations from position for attack, attack, neck bite, drag, shake, oblique attack, position for lunge attack and lunge attack. These behavioural patterns represent all the offensive behaviours ('initiating the aggressive interaction').

(b) 'Total neck bite' is the combined behavioural sub-class consisting out of the total durations of neck bite, drag and shake. These three behavioural patterns are reported as the most aggressive in the behavioural repertoire of ferrets and polecats (Staton and Crowell-Davis, 2003; Poole, 1974, 1978).

(2) 'Play' is the combined behavioural class of locomotory play and rough and tumble play.

(3) 'Social' combined the patterns ano-genital-, nose-neck- and nose-nose-investigation.

To evaluate the male sexual behaviour in experiment 3, not all behavioural patterns that were scored during the observation were used for further statistical analyses. We added the most important relevant behavioural patterns to the ethogram: neck gripping and mounting (Baum, 1976; Baum et al., 1983; Carroll et al., 1988; Lambert and Baum, 1991). As we decided to interrupt the copulations, the pattern pelvic thrusting was not observed in this study. We analysed neck gripping, mounting, the classes 'total offensive and defensive', 'play' and 'social' and the latency period in neck gripping. The latency in neck gripping was supposed to reveal to the motivation of the animals to perform reproductive behaviour. Although 'neck biting' and 'neck gripping' are visually undistinguishable, we prefer in experiment 3 the term 'neck gripping' to stress the sexual context of the behavioural patterns which is in line with Baum (1976), Carroll et al. (1988) and Lambert and Baum (1991).

2.4.2. Statistics

To compare the three experimental groups of animals the average of the three (or four) observations per subject were used as statistical unit for further analysis. All data were analysed using SPSS 12.0 for Windows. As a Kolmogorov-Smirnov-test showed that most variables were not normally distributed, nonparametric tests were used for statistical analysis.

A Kruskal-Wallis-test (KW) was used to test for overall differences between the three experimental groups. Mann-Whitney $U$-tests (MWU) were conducted for post hoc testing between two experimental groups if the KW test had shown overall significant differences. All statistics were two-tailed tested. Results are given in mean \pm S.E.M. and are considered non-significant when $p>0.05$. 

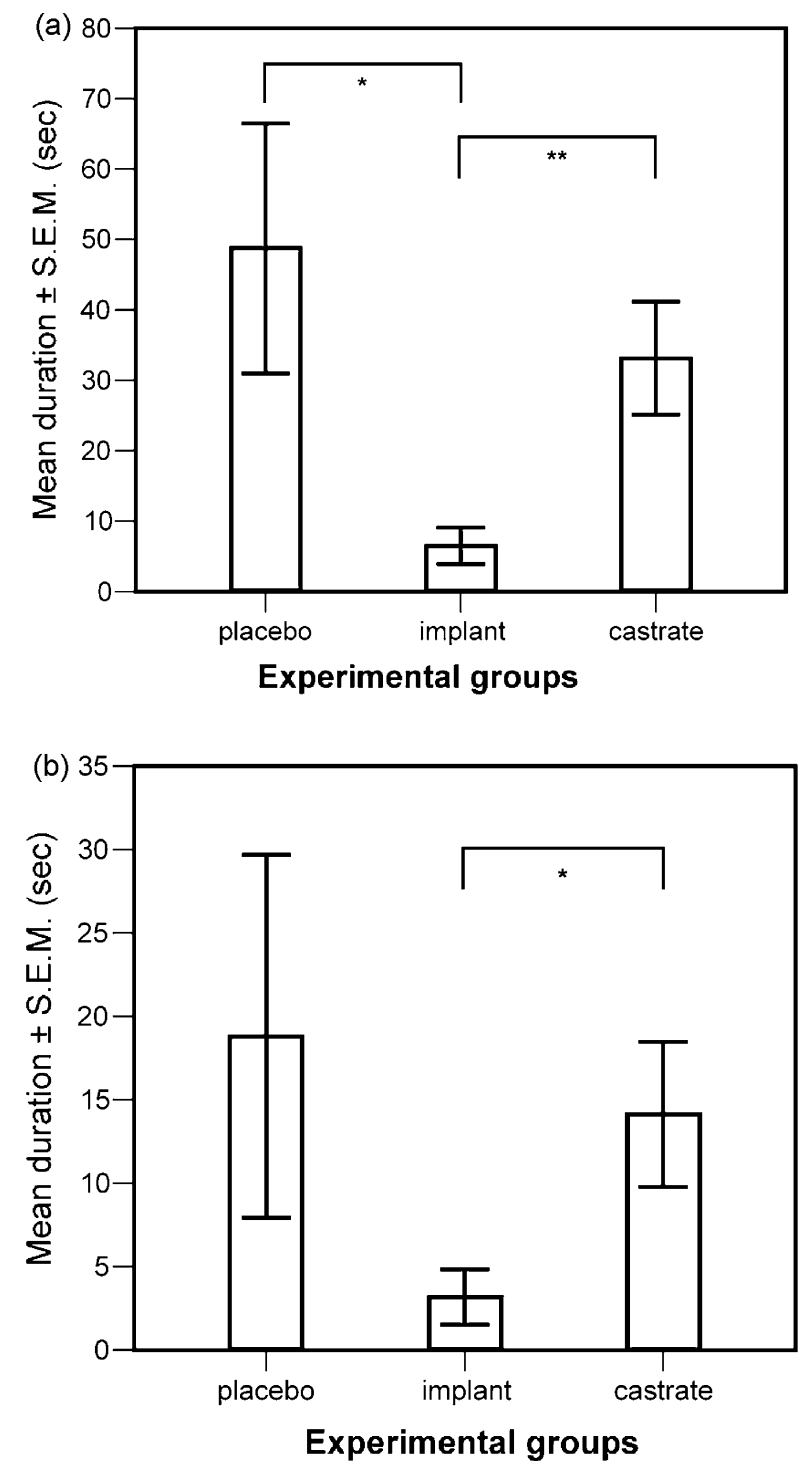

Fig. 1. Total mean duration ( \pm S.E.M. in $s$ ) of two different behavioural parameters (classes: a, 'total offensive and defensive'; b, 'total neck bite') in experiment $1\left({ }^{*} p \leq 0.05\right.$; ** $\left.p \leq 0.01\right)$.

\section{Results}

\subsection{Experiment 1: male-male confrontation without receptive female}

For the behavioural class 'total offensive and defensive' the results showed an overall significant difference between the three experimental groups $\left(\mathrm{KW}: \chi^{2}=8.95\right.$, d.f. $\left.=2, p \leq 0.01\right)$. The deslorelin-implant group showed significantly less 'total offensive and defensive' behaviour than both other groups (deslorelin-implant group: $6.49 \mathrm{~s} \pm 2.58$ versus placebo group: $48.73 \mathrm{~s} \pm 17.75$ and castrated group: $33.15 \mathrm{~s} \pm 8.01$; MWU: $U \geq 4.00, p \leq 0.05$ ) (Fig. 1a).

To elucidate the level of the actual initiation of the aggressive interactions in more detail, the sub-class 'total offensive behaviour' was analysed separately. The results showed an overall 


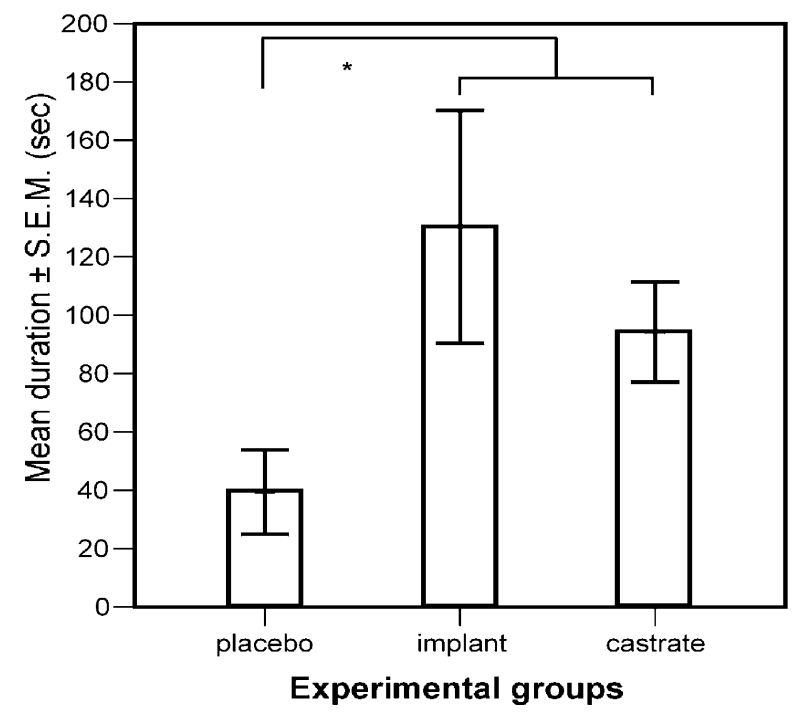

Fig. 2. Total mean duration ( \pm S.E.M. in $\mathrm{s})$ of the behavioural class 'play' in experiment $1\left({ }^{*} p \leq 0.05\right)$.

significance ('total offensive behaviour': $\mathrm{KW}: \chi^{2}=7.36$, d.f. $=2, p \leq 0.05$ ). Post hoc analyses of this sub-class showed that deslorelin-implant animals expressed significantly less offensive behaviour than castrated animals (deslorelin-implant group: $5.46 \mathrm{~s} \pm 2.48$ S.E.M. versus castrated group: $22.78 \mathrm{~s} \pm 4.76$; MWU: $U=4.00, p \leq 0.01$ ). No significant differences were found for the comparison between the deslorelin-implant group and the placebo group (MWU: $U=9.00, p=0.09$ ). Furthermore, no significant differences were found between the placebo and castrated group neither for the behavioural classes 'total offensive and defensive', nor for the class 'total offensive behaviour' (MWU: $U>15.00, p>0.39$ ).

Fig. $1 \mathrm{~b}$ shows the total mean duration of the behavioural sub-class 'total neck bite'. A separate analysis of this sub-class was chosen to show the level of three of the most prominent aggressive patterns (see Section 2.4.1). Overall between-groups analyses showed that there was a significant difference $\left(\mathrm{KW}: \chi^{2}=6.09\right.$, d.f. $\left.=2, p \leq 0.05\right)$ : the deslorelin-implant group showed a shorter total duration of neck biting behaviour than castrated animals (i.e. deslorelin-implant group: $3.2 \mathrm{~s} \pm 1.67$ versus castrated group: $14.1 \mathrm{~s} \pm 4.35$; MWU: $U=6.00, p \leq 0.05$ ). No significant differences were found between the deslorelin-implant group and the placebo group (MWU: $U=9.00, p=0.09$ ) or between the placebo group and the castrated group (MWU: $U=18.00$, $p=0.67)$.

Fig. 2 shows that in particular the ferrets in the placebo group played less. An overall significant difference between the groups was found for the total mean duration of the class 'play' (KW: $\chi^{2}=6.14$, d.f. $=2, p \leq 0.05$ ), whereby the post hoc testing showed that the placebo group played significantly less than both the deslorelin-implant group and castrate group (placebo group: $39.42 \mathrm{~s} \pm 14.50$ S.E.M. versus deslorelin-implant group: $130.33 \mathrm{~s} \pm 39.92$ and castrate group: $94.28 \mathrm{~s} \pm 17.16$, respectively; MWU: $U \geq 6.00, p \leq 0.05$ ). No significant differences were found between the deslorelin-implant group and the castrate group (MWU: $U=23.00$; $p=0.85$ ).

For the class 'social' a trend towards significance was found for an overall group difference $\left(\mathrm{KW}: \chi^{2}=5.68\right.$, d.f. $=2, p=0.06$ ). Finally, in experiment 1 , no significant differences were found between the three experimental groups for the separate behavioural patterns as mentioned in the ethogram (Table 1a). 

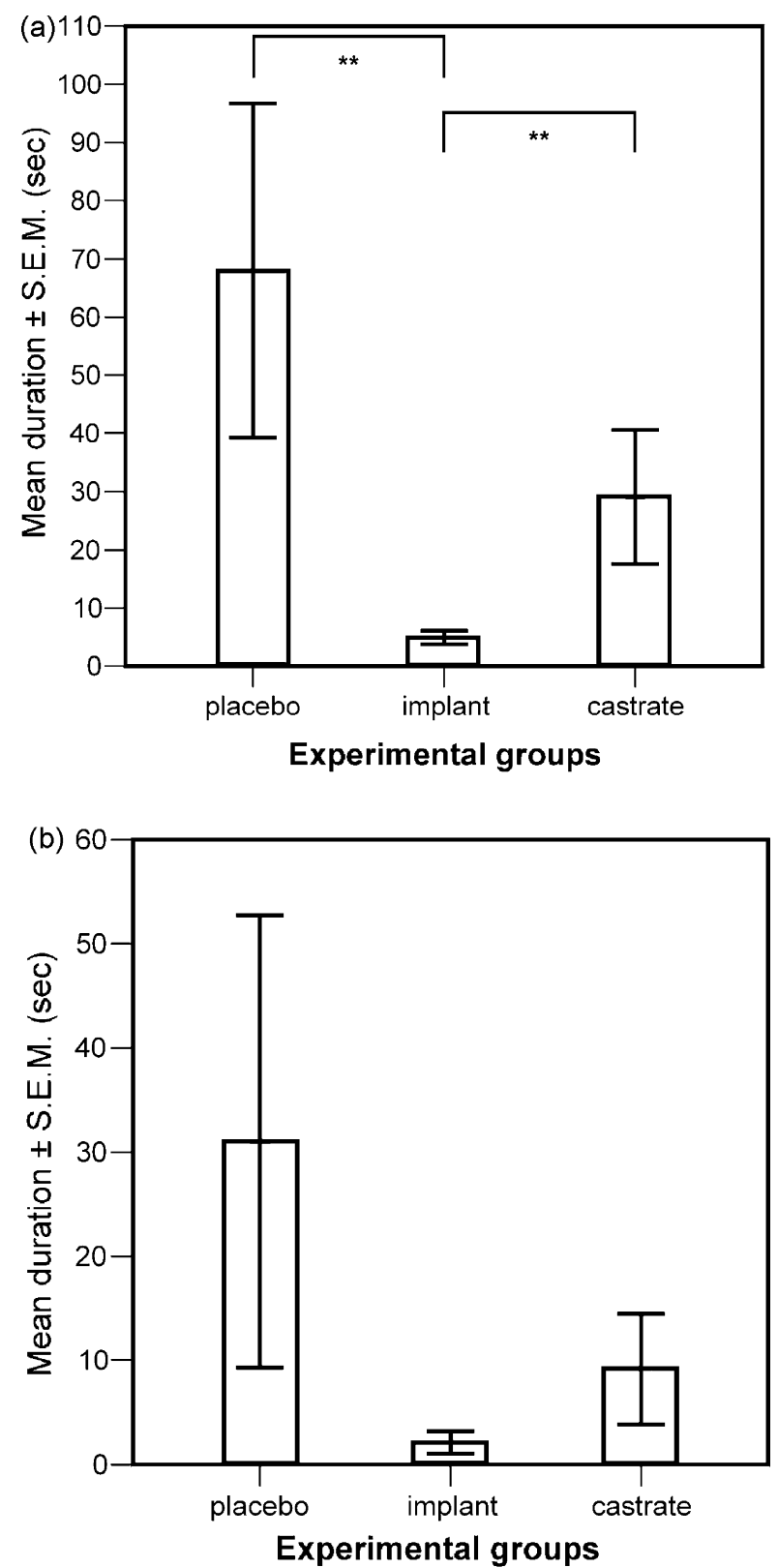

Fig. 3. Total mean duration ( \pm S.E.M. in s) of two different behavioural parameters (classes: a, 'total offensive and defensive; $\mathrm{b}$, 'total neck bite') in experiment $2\left({ }^{* *} p \leq 0.01\right)$.

\subsection{Experiment 2: male-male confrontation in presence of a receptive female}

An overall significant difference between the groups was found for the behavioural class 'total offensive and defensive' (KW: $\chi^{2}=12.59$, d.f. $=2, p \leq 0.01$ ), whereby the deslorelin-implant group again showed less offensive and defensive behaviours $(4.93 \mathrm{~s} \pm 1.21)$ compared to both the castrated animals and placebo animals (castrate group: $29.08 \mathrm{~s} \pm 11.47$ and placebo group: $67.99 \mathrm{~s} \pm 28.76$, respectively; MWU: $U \geq 1.00, p \leq 0.01$, see Fig. 3a). Furthermore, no 

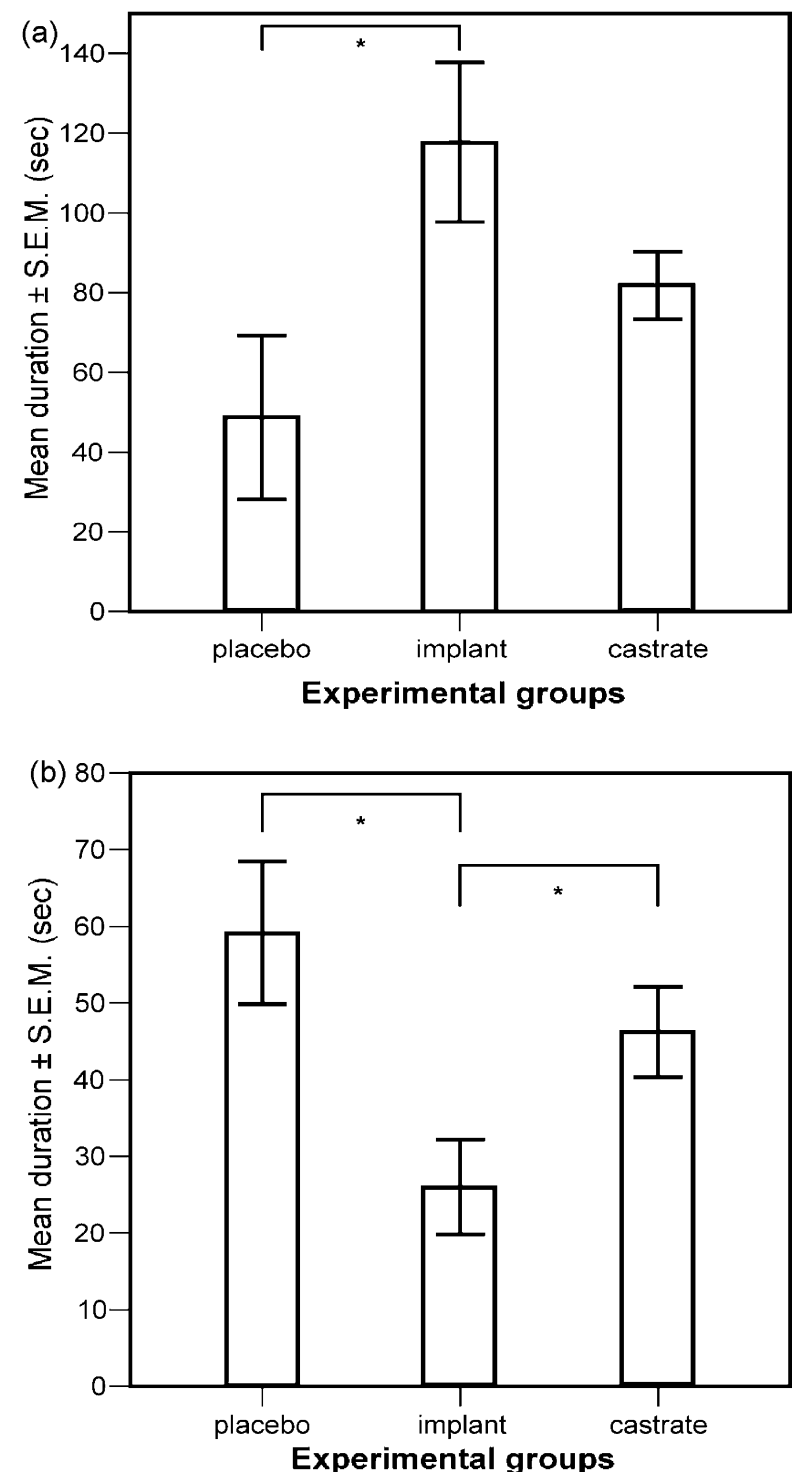

Fig. 4. Total mean duration ( \pm S.E.M. in s) of the behavioural classes 'play' (a) and 'social' (b) in experiment 2 $(* p \leq 0.05)$.

significant differences were found between the three experimental groups for either of the behavioural sub-classes 'total offensive' and 'total neck bite' ('total offensive': KW: $\chi^{2}=4.93$, d.f. $=2, p=0.09$ and 'total neck bite': KW: $\chi^{2}=2.51$, d.f. $=2, p=0.29$, see Fig. $3 b$ ).

Fig. 4a shows the duration of play behaviour in the three groups. Statistical testing showed that there was an overall significant difference for the behavioural class 'play' (KW: $\chi^{2}=6.09$, d.f. $=2, p \leq 0.05$ ): deslorelin-implant animals played significantly more than the animals of the placebo group (deslorelin-implant group: $117.78 \mathrm{~s} \pm 19.95$ versus placebo group: $48.71 \mathrm{~s} \pm 20.54$; MWU: $U=7.00, p \leq 0.05$ ). No significant differences were found in the class 'play' between the animals of the placebo group and the castrate group (MWU: $U=9.00$, $p=0.09)$. 


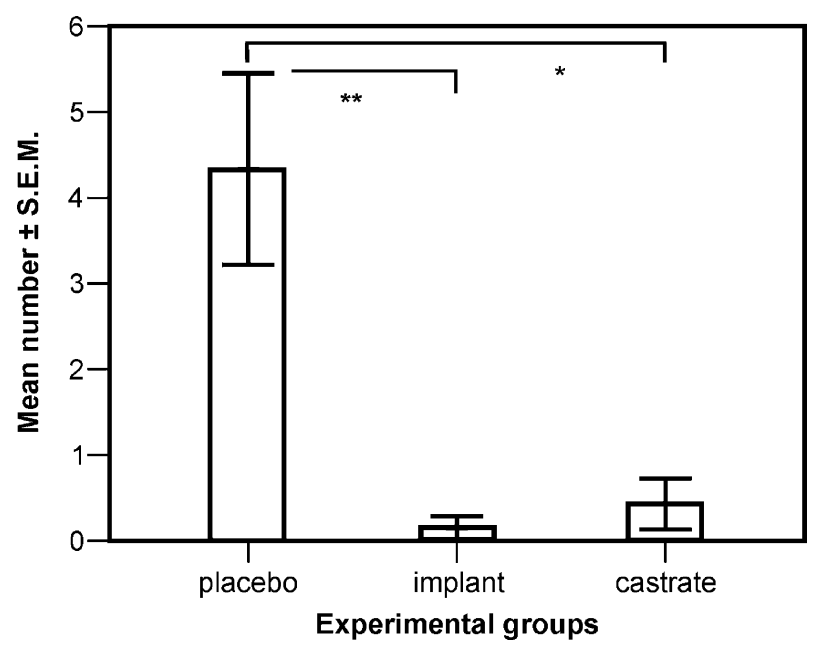

Fig. 5. Mean number of mounts ( \pm S.E.M.) performed by the ferret males in experiment $3\left(*^{*} p \leq 0.05 ; * * \leq 0.01\right)$.

For the class 'social' an overall significant difference was found between the experimental groups (KW: $\chi^{2}=7.35$, d.f. $=2, p \leq 0.05$ ), whereby the deslorelin-implant group did significantly less social investigations than both the placebo group and the castrate group (deslorelin-implant group: $26.01 \mathrm{~s} \pm 6.19$ versus placebo group: $59.15 \mathrm{~s} \pm 9.29$ and castrate group: $46.23 \mathrm{~s} \pm 5.85$; MWU: $U \geq 5.00, p \leq 0.05$, Fig. 4b).

In experiment 2 , no significant differences were found between the experimental groups for the separate behavioural patterns as mentioned in the ethogram (Table 1a), except for the pattern 'follow': subjects of the castrate group followed their interaction partners significantly more compared to both the deslorelin-implant and the placebo group (MWU: $U \geq 7.00$, $p \leq 0.05)$.

\subsection{Experiment 3: male sexual behaviour in a male-female confrontation}

The placebo animals mounted the females more than the males from the deslorelin-implant and castrated group (mean number of mounts: placebo group: $4.33 \pm 1.12$ versus deslorelinimplant group: $0.14 \pm 0.14$ and castrate group: $0.43 \pm 0.30 ; \mathrm{KW}: \chi^{2}=9.92$, d.f. $=2, p=0.007$ ). This difference was significant between the placebo group compared to both the deslorelinimplant group (MWU: $U=4.00, p \leq 0.01$ ) and the castrated group (MWU: $U=4.50, p \leq 0.05$, see Fig. 5).

Fig. 6 shows that there was an overall difference in the total mean duration of neck gripping between the three experimental groups $\left(\mathrm{KW}: \chi^{2}=6.90\right.$, d.f. $\left.=2, p \leq 0.05\right)$. Post hoc analysis showed that the males from the castrate group showed a significantly higher total mean duration of neck gripping behaviour toward the females compared to the deslorelin-implant group (castrate group: $30.86 \mathrm{~s} \pm 9.57$ versus deslorelin-implant group: $9.42 \mathrm{~s} \pm 5.29$; MWU: $U=7.00$, $p \leq 0.05)$. No overall difference was found between the three experimental groups in the latency period to neck gripping (KW: $\chi^{2}=2.01$, d.f. $=2, p=0.37$ ).

In Fig. 7 it can be seen that the animals of the placebo group clearly played less compared to the other experimental groups. Overall, this difference was significant (class 'play': KW: $\chi^{2}=12.05$, d.f. $=2, p \leq 0.01$ ). Further post hoc analysis showed that the animals from the placebo group played less than both the castrated and the deslorelin-implanted animals (placebo 


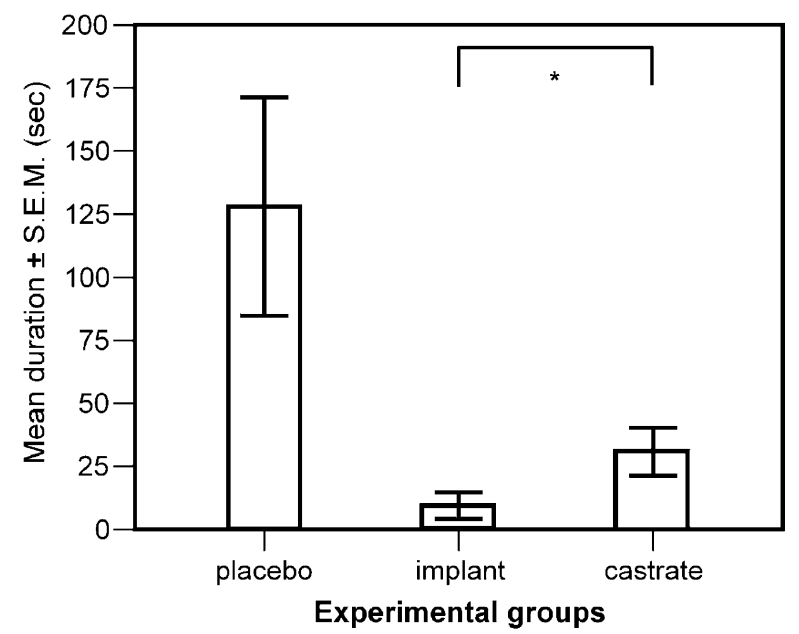

Fig. 6. Total mean duration ( \pm S.E.M. in $s)$ of neck gripping in experiment $3\left({ }^{*} p \leq 0.05\right)$.

group: $27.30 \mathrm{~s} \pm 11.80$ versus castrate group: $185.38 \mathrm{~s} \pm 27.30$ and deslorelin-implant group: $168.98 \mathrm{~s} \pm 22.59$, respectively; MWU: $U \geq 0.00, p \leq 0.01$ ). No differences in play behaviour were found between the castrate group and the implant group (MWU: $U=22.00, p=0.81$ ).

Furthermore, no overall significant differences were found in the total mean duration for the behavioural class 'social' $\left(\mathrm{KW}: \chi^{2}=1.35\right.$, d.f. $=2, p=0.51$ ), nor for behavioural patterns that concerned offensive or defensive interactions, except for the defensive behavioural pattern 'ward off', i.e. flank is directed towards an adversary ( KW: $\chi^{2}=8.18$, d.f. $=2, p \leq 0.05$ ). The deslorelin-implant group showed more "ward off' behaviour than both the two other experimental groups (deslorelin-implant group: $9.14 \mathrm{~s} \pm 3.03$ versus placebo group: $0.00 \mathrm{~s} \pm 0.00$ S.E.M. and castrate group: $0.96 \mathrm{~s} \pm 0.69$; MWU: $U \geq 6.00, p \leq 0.05$ ).

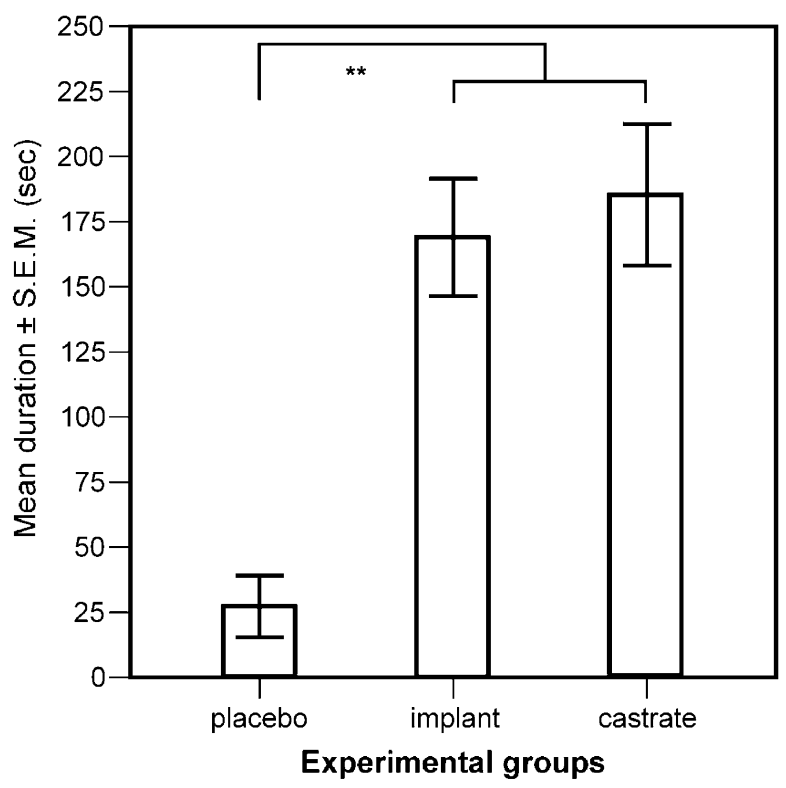

Fig. 7. Total mean duration ( \pm S.E.M. in $s)$ of the behavioural class 'play' in experiment $3\left({ }^{* *} p \leq 0.01\right)$. 


\section{Discussion}

The present study aimed to assess the effects of a chemical castration with a deslorelinimplant in the male ferret, as an alternative for surgical castration, on the occurrence of intermale aggression, sexual behaviour and play behaviour. The main results were that: (1) chemical castration with the $\mathrm{GnRH}$ agonist deslorelin results in a decrease in the occurrence of aggressive behaviour between male ferrets both in the presence and absence of a receptive female. In addition, our data showed that a deslorelin castration had more effect on the reduction of aggression than surgical castration; (2) sexually motivated behavioural patterns were reduced in the deslorelin and surgical castrated group in the male-female confrontation; (3) the deslorelin group, and to a lesser extent the surgically castrated group, had a higher incidence of play behaviour in comparison to intact males in the intermale confrontation tests. These findings, especially with regard to the placebo and deslorelin implanted animals, correspond to our expectations that deslorelin will diminish aggressive behaviour, because testosterone and related compounds (estradiol and dihydrotestosterone [DHT]) are important for the regulation of aggressive behaviour in male animals (Giammanco et al., 2005). The study of Schoemaker et al. (2008), which separately presents the hormonal part of the current study, confirms this expected decrease of aggression-related hormones. As one of the major motivations for surgical castration in practice is the reduction of aggression, our finding that the surgical castration barely had an effect on aggression in ferrets is rather surprising. It shows that the decrease of testosterone levels to near-zero levels, as found in both the deslorelin and castrated group (Schoemaker et al., 2008), is in itself not enough to reduce aggression in ferrets. The lack of effectiveness of surgical castration on reducing aggression in ferrets affirms the study of Staton and Crowell-Davis (2003) who reported no difference in aggressive behaviour between surgically castrated and intact male pairs. However, their results were inconclusive because of the low sample size in combination with dichotomous data (whether or not a fight occurred). Also for other species, mainly birds (e.g. Pinxten et al., 2003) but also mammals (e.g. Demas et al., 1999), however, it was found that surgical castration did not reduce aggression. Part of the ineffectiveness of surgical castration might be attributed to species differences, seasonality and age of castration (Trainor et al., 2006). Our findings raise an interesting additional point as in contrast to surgical castration, chemical castration with deslorelin did have an effect on aggression. One of the most likely explanations is that deslorelin as a GnRH agonist decreases the plasma estradiol level, which is also involved in the regulation of aggression (Trainor et al., 2006). Additionally, surgical castration may lead to elevated GnRH and LH levels in the blood, which may result in some testosterone-related compound production in tissues other than the testes. The most logical tissue would be the adrenal gland. As is shown in several studies, ferrets with hyperadrenocorticism have elevated plasma concentration of estradiol, 17- $\alpha$-hydroxyprogesterone, androstenedione, and dehydroepioandrosterone sulphate (e.g. Rosenthal and Peterson, 1996). Some of these hormones might have an effect on the behaviour of the affected ferret and it is mentioned that ferrets with hyperadrenocorticism are indeed more aggressive and that these symptoms can be decreased by using a GnRH agonist (Wagner et al., 2005). In some other species, androstenedione is also considered to elevate aggressive behaviour (Swiss-Webster mice: Luttge and Hall, 1973; golden hamster: Payne, 1974). It is therefore possible that after a short period the increased levels of LH after surgical castration will lead to elevated plasma concentrations of the mentioned hormones, in particular androstenedione.

Another result of interest is the increased levels of play behaviour in the castrated group and in the deslorelin-implant group in particular. Also this result might be explained by lower plasma 
testosterone levels in these two groups (Schoemaker et al., 2008): less testosterone leads to less dominant behaviour, hence less agonistic interactions, which subsequently results in more play behaviour due to less stressful (competitive) conditions. This finding is in agreement with the findings in the literature showing that play behaviour is often seen under familiar and relaxed conditions (e.g. Fagen, 1981; Grier and Burk, 1992; Broom and Johnson, 1993) and does not occur under severe stress (Hinton and Dunn, 1967; McCune, 1992). Additionally, as the actual performance of play behaviour is known to be opioid mediated (Vanderschuren et al., 1995a,b), it is expected that play patterns have rewarding properties ("pleasure") for the animal. The increased levels of play, hence increased rewarding experiences, can improve the animal's welfare (this in addition to the already discussed decreased level of agonistic patterns) (see also Vinke et al., 2005).

Two aspect of play behaviour should be studied for this species in more detail in future studies: (1) aggressive interactions often resulted from a sudden switch from play behaviour into more aggression-motivated behavioural patterns (i.e. 'play escalation'). Information on this relation is important for the further assessment and evaluation of the welfare of ferrets; (2) the observed "ward off" behaviour in experiment 3, which was originally classified under the defensive patterns as based on Poole $(1974,1978)$. However, during our observations we got more and more the impression that "ward off" is also an element in ferret play behaviour, especially in the more relaxed male-female context. This behavioural element "ward off" can also be seen in mink play (Vinke, 2002, personal observation). This would also explain why this pattern was significantly higher in the deslorelin-implant group.

The significant differences in the main behavioural classes during the three experiments were all in the same direction: the deslorelin-implant group showed less aggressive interactions, less sexual behaviour and more play behaviour. Moreover, in many cases the differences in some other behavioural categories were in the same direction, but just above the significance level (showing a trend). Because of this clear directionality of the results, and hence the relative small impact of a type I error, we refrained from correction for multiple testing, as it would decrease the power considerably as a result of the small sample sizes as used in this study (i.e. $N_{1,2,3}=6,7,7$ ). Future studies can consider larger sample sizes.

In conclusion: the present study showed that chemical castration with the GnRH agonist deslorelin was more effective in decreasing aggressive behaviour in male ferrets than surgical castration. In comparison to the placebo-treated group both the surgically and chemically castrated group showed more play behaviour and less sexual behaviour. This shows that a reduction of testosterone levels is in itself not enough to reduce aggression in ferrets, but it might affect sexually motivated behaviour and play behaviour. Especially the increase of play behaviour might be an indicator of improved welfare. Taken together, deslorelin chemical castration is a suitable alternative for surgical castration, and may be preferred due to the serious medical problems associated with surgical castration in ferrets.

\section{Acknowledgements}

We would like to thank the animal tenders of the Division of Avian and Exotic Animal Medicine of the Veterinary Faculty of the Utrecht University, who helped with different parts of the study. We especially thank Ms. A. Strookappe for the skilful technical assistance and Ms. A. Kuijten for explaining the daily routine and for her help with statistics. This study was made possible by the generous support from the Martine de Beukelaar foundation and "Stichting de Fret". 


\section{References}

Applegate, J.A., Walhout, M.F., 1998. Childhood risks from the ferret. J. Emerg. Med. 16 (3), 425-427.

Baum, J.M., 1976. Effects of testosterone propionate administered perinatally on sexual behavior of female ferrets. J. Comp. Physiol. Psychol. 90, 399-410.

Baum, M.J., Canick, J.A., Erskine, M.S., Gallagher, C.A., Shim, J.H., 1983. Normal differentiation of masculine sexual behaviour in male ferrets despite neonatal inhibition of brain aromatase or 5-alpha-reductase activity. Neuroendocrinology 36, 277-284.

Beaver, B.V., 1983. Clinical classification of canine aggression. Appl. Anim. Ethol. 10, 35-43.

Broom, D.M., Johnson, K.G., 1993. Stress and Animal Welfare. Chapman and Hall, London, UK.

Carroll, R.S., Weaver, C.E., Baum, M.J., 1988. Evidence implicating aromatization of testosterone in the regulation of male ferret sexual behavior. Physiol. Behav. 42, 457-460.

Demas, G.E., Moffatt, C.A., Drazen, D.L., Nelson, R.J., 1999. Castration does not inhibit aggressive behavior in adult male prairie voles (Microtus ochrogaster). Physiol. Behav. 66 (1), 59-62.

Dunstone, N., 1993. The Mink. T and AD Poyser, London, UK.

D’Occhio, J.M., Aspden, W.J., 1996. Characteristics of luteinizing hormone and testosterone secretion, pituitary responses to LH-releasing hormone (LHRH), and reproductive function in young bulls receiving the LHRH agonist deslorelin: effect of castration on LH responses to LHRH. Biol. Reprod. 54, 45-52.

D’Occhio, M.J., Fordyce, G., Whyte, T.R., Aspden, W.J., Trigg, T.E., 2000. Reproductive responses of cattle to GnRH agonists. Anim. Reprod. Sci. 60-61, 433-442.

Fagen, R., 1981. Animal Play Behaviour. Oxford University Press, New York, USA.

Giammanco, M., Tabacchi, G., Giammanco, S., Di Majo, D., La Gaurdia, M., 2005. Testosterone and aggressiveness. Med. Sci. Monit. 1, 136-145.

Grier, J.W., Burk, T., 1992. Biology of Animal Behaviour, 2nd ed. Mosby-Year Book Inc., MO, USA.

Hinton, H.E., Dunn, A.M.S., 1967. Mongooses, Their Natural History and Behaviour. Oliver and Boyd Ltd., London, UK.

Johnson, C.A., Thompson Jr., D.L., Cartmill, J.A., 2003. Effects of deslorelin acetate implants in horses: single implants in stallions and steroid-treated geldings and multiple implants in mares. J. Anim. Sci. 81, 1300-1307.

Lambert, G.M., Baum, M.J., 1991. Reciprocal relationships between pulsatile androgen secretion and the expression of mating behavior in adult male ferrets. Horm. Behav. 25, 382-393.

Luttge, W.G., Hall, N.R., 1973. Androgen-induced agonistic behaviour in castrate male Swiss-Webster mice: comparison of for naturally occurring androgens. Behav. Biol. 8, 725-732.

McCune, S., 1992. Temperament and the welfare of caged cats. PhD Thesis. University of Cambridge, UK.

Payne, A.P., 1974. A comparison of the effects of androstenedione, dihydrotestosterone and testosterone propionate on aggression in the castrated male golden hamster. Physiol. Behav. 13, 21-26.

Pinxten, R., de Ridder, E., de Cock, M., Eens, M., 2003. Castration does not decrease non-reproductive aggression in yearling male European starlings (Sturnus vulgaris). Horm. Behav. 43, 394-401.

Poole, T.B., 1966. Aggressive play in polecats. Symp. Zool. Soc. Lond. 18, $23-44$.

Poole, T.B., 1973. The aggressive behaviour of individual male polecats (Mustela putorius, M. furo and hybrids) towards familiar and unfamiliar opponents. J. Zool. Lond. 170, 395-414.

Poole, T.B., 1974. Detailed analysis of fighting in polecats (Mustelidae) using ciné film. J. Zool. Lond. 173, 369-393.

Poole, T.B., 1978. An analysis of social play in polecats (Mustelidae) with comments on the form and evolutionary history of the open mouth play face. Anim. Behav. 26, 36-49.

Quesenberry, K.E., Carpenter, J.W., 2004. Ferrets, Rabbits and Rodents: Clinical Medicine and Surgery, 2nd ed. WB Saunders Co., Philadelphia, USA.

Ronayne, E., Enright, W.J., Roche, J.F., 1993. Effects of continuous administration of gonadotropin-releasing hormone $(\mathrm{GnRH})$ or a potent $\mathrm{GnRH}$ analogue on blood luteinizing hormone and testosterone concentrations in prepubertal bulls. Domest. Anim. Endocrinol. 10, 179-189.

Rosenthal, K.L., Peterson, M.E., 1996. Evaluation of plasma androgen and estrogen concentrations in ferrets with hyperadrenocorticism. J. Am. Vet. Med. Assoc. 209, 1097-1102.

Schoemaker, N.J., Schuurmans, M., Moorman, H., Lumeij, J.T., 2000. Correlation between age at neutering and age at onset of hyperadrenocorticism in ferrets. J. Am. Vet. Med. Assoc. 216, 195-197.

Schoemaker, N.J., Teerds, K.J., Mol, J.A., Lumeij, J.T., Thijssen, J.H., Rijnberk, A., 2002. The role of luteinizing hormone in the pathogenesis of hyperadrenocorticism in neutered ferrets. Mol. Cell. Endocrinol. 197, 117-125.

Schoemaker, N.J., van Deijk, R., Muijlaert, B., Kik, M.J.L., Kuijten, A.M., de Jong, F.H., Trigg, T.E., Kruitwagen, C.L.J.J., Mol, J.A., 2008. Use of a gonadotropin releasing hormone agonist implant as an alternative for surgical castration in male ferrets (Mustela putorius furo). J. Theriogenol., in press 
Staton, V.W., Crowell-Davis, S.L., 2003. Factors associated with aggression between pairs of domestic ferrets. J. Am. Vet. Med. Assoc. 222 (12), 1709-1712.

Trainor, B.C., Kyomen, H.H., Marler, C.A., 2006. Estrogenic encounters: how interactions between aromatase and the environment modulate aggression. Front. Neuroendocrinol. 27, 170-179.

Trigg, T.E., Wright, P.J., Armour, A.F., Williamson, P.E., Junaidi, A., Martin, G.B., Doyle, A.G., Walsh, J., 2001. Use of a GnRH analogue implant to produce reversible long-term suppression of reproductive function in male and female domestic dogs. J. Reprod. Fertil. Suppl. 57, 255-261.

Vanderschuren, L.J.M.J., Spruijt, B.M., Hol, T., Niesink, R.J., van Ree, J.M., 1995a. Sequential analysis of social play behavior in juvenile rats: effects of morphine. Behav. Brain Res. 72 (1-2), 89-95.

Vanderschuren, L.J.M.J., Stein, E.A., Wiegant, V.M., van Ree, J.M., 1995b. Social play alters regional brain opioid receptor binding in juvenile rats. Brain Res. 680 (1-2), 148-156.

Vinke, C.M., 2004. Cage enrichments and welfare of farmed mink. PhD Thesis, University of Utrecht. Universal Press, Veenendaal, The Netherlands.

Vinke, C.M., van Leeuwen, J., Spruijt, B.M., 2005. Juvenile farmed mink (Mustela vison) with additional access to swimming water play more frequently than animals housed with cylinder and platform, but without swimming water. Anim. Welf. 14, 53-60.

Wagner, R.A., Bailey, E.M., Schneider, J.F., Oliver, J.W., 2001. Leuprolide acetate treatment of adrenocortical disease in ferrets. J. Am. Vet. Med. Assoc. 218, 1272-1274.

Wagner, R.A., Piché, C.A., Jöchle, W., Oliver, J.W., 2005. Clinical and endocrine responses to treatment with deslorelin acetate implants in ferrets with adrenocortical disease. Am. J. Vet. Res. 66, 910-914.

Wright, J.C., Nesselrote, M.S., 1987. Classification of behavior problems in dogs: distributions of age, breed, sex and reproductive status. Appl. Anim. Behav. Sci. 19, 169-178. 